ORIGINAL PAPER

\title{
ExPRESSION OF $\beta$-CATENIN AND ITS CORRELATION \\ WITH METASTATIC PROGRESSION OF ESOPHAGOGASTRIC JUNCTION ADENOCARCINOMA
}

\author{
Janusz WlodarczyK ${ }^{1}$, Lucyna Rudnicka-Sosin ${ }^{2}$, Jaroseaw Kużdżą ${ }^{1}$
}

${ }^{1}$ Department of Thoracic Surgery, Jagiellonian University Collegium Medicum, Krakow, Poland

${ }^{2}$ Department of Pathology, John Paul II Hospital, Krakow, Poland

The evaluation of $\beta$-catenin expression in adenocarcinoma of the esophagogastric junction and its influence on cancer progression.

Sixty-one patients who were diagnosed with adenocarcinoma of the esophagogastric junction were examined. We evaluated $\beta$-catenin distribution in the cell membrane and the cell nucleus in adenocarcinoma of the esophagogastric junction type 1 and type 3 .

Our findings showed lack of a statistically significant difference in evaluation of adenocarcinoma type 1 and type 3 aggressiveness. However, we found a statistically significant association with the $\mathrm{T}$ and $\mathrm{N}$ stage, although we did not find an effect of them on patient survival.

Patients with cellular membrane and cell nucleus staining comprise a group of patients with higher risk of malignancy progression in adenocarcinoma of the esophagogastric junction types 1 and 3 .

Key words: $\beta$-catenin, esophago-gastric junction, adenocarcinoma.

\section{Introduction}

In the last decades the incidence of esophagogastric junction adenocarcinoma has been rising. At the same time, the incidence of squamous cell carcinoma has been declining or remains the same. Despite radical surgical and radio/chemotherapy, survival rates are not satisfactory and the risk and evaluation of carcinoma relapse are uncertain $[1,2]$. The identification of patients with higher risk of carcinoma relapse would facilitate therapeutic treatment strategy significantly.

Due to progress in immunohistochemistry and molecular diagnostics, the role of cell adhesion molecules has become more accurate and understandable. $\beta$-catenin was described as an element of the E-cadherin/catenin complex. In healthy cells catenin is united with adherin, but its action depends on APC (adeno- matous polyposis coli) and phosphorylation by serine-threonine kinase GSK-3B. In the event of mutations, the phosphorylation process becomes disturbed and $\beta$-catenin passes into the cell's nucleus with LEF (lymphocyte enhancer factor)/TCF (T cell factor). It turns out that such action may decode the reaction which through MMP-7 (matrix metalloproteinase 7), cyclin D1, MDR 7 (multidrug resistance gene) and later through $\mathrm{AD}-1$ and fra- 1 may start the process of carcinogenesis or tumor progression $[3,4]$. The role of the E-cadherin/catenin complex in adenocarcinoma of the esophagogastric junction is unclear. The aim of this study is to assess the influence of $\beta$-catenin expression on the metastatic potential of adenocarcinomas localized in the esophagogastric junction. 


\section{Material and methods}

\section{Patients}

Sixty-one patients with confirmed adenocarcinoma of the gastroesophageal junction were included in the study. According to the Siewert and Stein classification [5] they were divided into three groups: patients with adenocarcinoma related to Barrett esophagus (AEG type I), adenocarcinoma of cardia (AEG type II) and subcardial adenocarcinoma (AEG type III). Only patients with type I and type III adenocarcinoma were included in this study because sometimes differentiation between type 2 and 3 in stage T3 or T4 makes difficulties in assessment [5]. The TNM UICC and Lauren classification was used for assessment of the disease stage $[6,7]$. Patients with AEG1 tumors underwent transmediastinal esophagectomy, proximal stomach and lymphadenectomy in the posterior mediastinum and celiac axis. An extended total gastrectomy with resection of the distal esophagus and D2 lymphadenectomy with transhiatal lymphadenectomy of the inferior mediastinum was the procedure for patients with AEG3 tumors. In total 1130 lymph nodes were removed during surgery, on average 22 lymph nodes per patient (range 8-58 lymph nodes). In 60 cases surgery was radical (R0), while 1 case was classified as R1. The mean follow-up time for the 61 patients was 27.4 months, with a range of 1-96.7 months. Table I shows clinical and histopathologic outcomes of patients.

\section{Immunohistochemistry}

Formalin-fixed, paraffin-embedded tissue specimens were cut into $6 \mu \mathrm{m}$ thick section which were placed onto silanized slides, then deparaffinized and rehydrated. Antigen retrieval was performed by means of a citric acid solution, $\mathrm{pH}$ 6.0, which was heated in a microwave oven for $1 \times 15 \mathrm{~min}$, at $650 \mathrm{~W}$. Endogenous peroxidase activity was blocked with a $0.2 \%$ hydrogen peroxide solution. The primary antibody was the $\beta$-catenin specific HEC-D1 monoclonal antibody (Takara Biomedicals, Takara Shuzo Japan) that was incubated for $1.5 \mathrm{~h}$ at room temperature at a dilution of $1: 1000$. Detection of the bound antibody was carried out with the avidin-biotin complex peroxidase method (ABC Elite kit, Eliot Burlingame CA), followed by staining with the peroxidase substrate 3,3-diaminobenzidine tetrachloride (DAB) (Sigma GmbH, Deisenhofen Germany). A light hematoxylin stain was used as the counterstain. As a negative control, the primary antibody was replaced with phosphate-buffered saline. Normal esophagus mucosa with membranous $(\mathrm{M}+)$ and no nuclear $(\mathrm{N}-)$ expression in the tissue section served as a positive control. Membranous (M) and nuclear expression of $\beta$-catenin was assessed. Membranous staining for $\beta$-catenin was classified as a normal $(3+)$, reduced (moderate) $(2+)$, weak $(1+)$ or negative (0). The percentage proportion of stained cells with complete membranous staining was recorded in the following categories: $0-0-10 \%, 1->10-40 \%$, $2-40-90 \%, 3->90 \%$. In addition, the presence and percentage of tumor cells exhibiting clear nuclear staining for $\beta$-catenin were noted and classified as $3+(>67 \%$ of the tumor cells), $2+(>33 \%$ and $<67 \%$ of the tumor cells), $1+(<33 \%$ of the tumor cell nuclei).

\section{Statistics}

The correlations between the immunohistochemical expression of membranous $\beta$-catenin, nuclear catenin staining, survival, grade of differentiation, lymph node metastases, tumor size, and Lauren classification were statistically compared using the $\chi^{2}$ test or Fisher's two-tailed test. Survival probabilities were calculated by the Kaplan-Meier method and compared by the $\log$ rank test. $\mathrm{P}$ values $<0.05$ were considered to be statistically significant.

\section{Results}

Sixty-one patients diagnosed with adenocarcinoma of the esophagogastric junction; 32 of them with type 1 and 29 with type 3 (Table I) were analyzed. Among patients with type 1 , in 21 we found reduction of cell membrane staining and/or cell nucleus staining with anti- $\beta$-catenin antibody. In 11 of them staining was normal and in 2 of them the reaction was negative. In patients with type 3 findings were as follows: in 21 patients we found cell membrane staining reduction and/or staining of the cell nucleus. In 8 patients staining was normal and in 1 patient the reaction was negative. Staining of cell nuclei was found in 9 patients (in 5 of them there was normal cell membrane staining) with type 1 and 11 (in 3 of them there was normal cell membrane staining) in type 3 (Table II). Among patients with staining reduction in type 1 (AEG 1) carcinomas, in 16 of them we found an intestinal type, in 2 diffuse type, and in 3 a mixed type (according to Lauren's classification). In patients with type 3 (AEG 3) in 15 patients we found intestinal type, in 4 patients a diffuse type and in 1 patient a mixed type. Staining of cell nuclei was found in 6 patients with an intestinal type, in 2 patients with a mixed type and in 1 patient with a diffuse type. Among patients with type 3 (AEG 3), in 8 of them we found an intestinal type, in 2 patients a diffuse type and in 1 patient a mixed type. In 12 patients we found both staining of the cell membrane and a nuclear reaction $(\mathrm{M}+, \mathrm{N}+)$. In 22 patients we found a reduction in cell membrane staining $(\mathrm{M}+$, $\mathrm{N}+)$ and in 8 patients cell nucleus staining. In 19 patients staining of the cell membrane was classified 
Table I. Clinical and pathomorphological data of patients with AEG1 and AEG3

\begin{tabular}{lccc}
\hline Group & AEG1 & AEG3 & TOTAL \\
\hline $\mathrm{N}$ & 32 & 29 & 61 \\
\hline Sex M : F & $26: 6$ & $23: 6$ & 61 \\
\hline Age & $45-75$ & $33-78$ & $33-78$ \\
\hline Follow-up & $27.7(1-96.7)$ & $26.6(1-91.7)$ & $27.4(1-96.7)$ \\
\hline Differentiation & $1: 16: 15$ & $0: 16: 13$ & $1: 32: 28$ \\
Grade G1 : G2 : G3 & $26: 3: 2$ & $19: 4: 6$ & $45: 7: 9$ \\
\hline Lauren type ( I : M : D) & T1N0M0 11 & T1N0M0 5 & T1N0M0 16 \\
\hline TNM & T2N0M0 3 & T2N0M0 6 & T2N0M0 9 \\
& T3N0M0 2 & T3N0M0 1 & T3N0M0 3 \\
& T1N1M0 1 & T1N1M0 1 & T1N1M0 2 \\
& T2N1M0 6 & T2N1M0 8 & T2N1M0 14 \\
& T3N1M0 7 & T3N1M0 1 & T3N1M0 8 \\
& T2N2M0 2 & T4N1M0 1 & T4N1M0 1 \\
\hline AEG 1 - adenocarcinoma of gastroesophageal junction type 1; AEG 3 - adenocarcinoma of gastroesophageal junction type 3; Lauren (I : M : D) - Lauren (intesti-
\end{tabular}

as stage 3 , and in 41 patients no nucleus staining was found.

In 3 patients the results were negative. Staining reduction correlated with lymph node metastases $(\mathrm{p}=0.048)$ and with $\mathrm{T}$ stage $(\mathrm{p}=0.041)$. However, staining distribution had no effect on patients survival. Its connection with Lauren's classification and degree of carcinoma differentiation (Table II) was not established.

\section{Discussion}

$\beta$-catenin is a member of the cell adhesion molecules, where together with E-cadherin it forms a group of interepithelial glycoproteins responsible for carrying out the function of adhesion with other membrane proteins. It has various subcellular locations occurring in the cell membrane, cytoplasm, and cell nucleus. The E-cadherin/catenin complex not only plays a role in the cell adhesion process but also plays a key role in a signal transmission from the external environment and through reaction with receptors it may create a particular malignant phenotype. Presumably, it may play an important role in initiation as well as progression of malignancy, as evidenced by changes in staining of the cell membrane as well as the cell nucleus $[8,9,10,11]$. Loss of the epithelium of a mucous membrane's integrity may be an hypothesis about the impact of this complex on phenotype change and malignancy progression.
It is considered that maintenance of cell adhesion is possible due to E-cadherin function connected with $\beta$-catenin in the cytoplasm. Krisdanatu and partners reported staining reduction of $\beta$-catenin in relation to differentiation and shorter survival, not finding it to be connected with $\mathrm{T}$ stage [9]. Wijahaven et al. reported that staining reduction was associated with T stage only. They did not observe its association with grade. There was no association between esophageal adenocarcinoma and carcinoma of a proximal part of the stomach [12]. In an earlier study, the authors analyzing 24 patients with adenocarcinoma of the esophagogastric junction observed a staining reduction in cell membrane, accumulation in cytoplasm $(54 \%, 75 \%, 67 \%, 63 \%)$ and nucleus relocation (25\%) for E-cadherin, $\alpha-, \beta-, \gamma$-catenin but without a correlation in relation to TNM classification [13]. In other reports, the authors note a strong association with shorter patient survival, in whom $\beta$-catenin staining reduction was found. Heaving realized that this feature constituted an independent prognostic factor, they stated that it may help in identification of patients with clinically negative lymph nodes, who are at risk of malignant disease progression. Some authors note that staining change or lack of it in patients with lymph node metastases may have a different character than in the original tumor, therefore they suggest that staining change may be the result of downregulation of other regulation $[12,14]$. Bian et al. found that staining reduction is associated with 
Table II. Correlation between $\beta$-catenin, nuclear catenin and prognostic factors in adenocarcinoma of the esophagogastric junction

\begin{tabular}{|c|c|c|c|c|}
\hline & $\mathrm{M}(+) \mathrm{N}(+)$ & $\mathrm{M}(+) \mathrm{N}(-)$ (FIG. 1) & $\mathrm{M}(-) \mathrm{N}(+)$ (FIG. 2) & P FOR T AND $\mathbf{N}$ \\
\hline Aeg 1 & 6 & 12 & 3 & \multirow{25}{*}{$\begin{array}{l}0.041 \\
0.048\end{array}$} \\
\hline Lauren & $4 \mathrm{i}, 1 \mathrm{~d}, 1 \mathrm{~m}$ & $10 \mathrm{i}, 1 \mathrm{~d}, 1 \mathrm{~m}$ & $2 \mathrm{i}, 1 \mathrm{~m}$ & \\
\hline \multirow[t]{3}{*}{ G } & G1- & G1 & G1 & \\
\hline & G2 1 & G3 5 & G2 1 & \\
\hline & G3 5 & G3 6 & G3 2 & \\
\hline \multirow[t]{4}{*}{$\mathrm{T}$} & $\mathrm{T} 1$ & $\mathrm{~T} 14$ & T1 1 & \\
\hline & $\mathrm{T} 23$ & $\mathrm{~T} 23$ & $\mathrm{~T} 22$ & \\
\hline & T3 3 & T3 5 & $\mathrm{~T} 3$ & \\
\hline & $\mathrm{T} 4$ & $\mathrm{~T} 4$ & $\mathrm{~T} 4$ & \\
\hline \multirow[t]{3}{*}{$\mathrm{N}$} & No 1 & N0 3 & No 2 & \\
\hline & N1 4 & N19 & N1 1 & \\
\hline & N2 1 & $\mathrm{~N} 2$ & $\mathrm{~N} 2$ & \\
\hline Aeg 3 & 6 & 10 & 5 & \\
\hline Lauren & $4 \mathrm{i}, 1 \mathrm{~d}, 1 \mathrm{~m}$ & $7 \mathrm{i}, 3 \mathrm{~d}$ & $4 \mathrm{i}, 1 \mathrm{~d}$ & \\
\hline \multirow[t]{3}{*}{ G } & G1 & G1 & G1 & \\
\hline & G2 2 & G2 6 & G2 4 & \\
\hline & G3 4 & G3 4 & G3 1 & \\
\hline \multirow[t]{4}{*}{$\mathrm{T}$} & T1 1 & T1 & T1 2 & \\
\hline & $\mathrm{T} 23$ & $\mathrm{~T} 28$ & $\mathrm{~T} 23$ & \\
\hline & T3 2 & T3 2 & $\mathrm{~T} 3$ & \\
\hline & $\mathrm{T} 4$ & $\mathrm{~T} 4$ & $\mathrm{~T} 4$ & \\
\hline \multirow[t]{3}{*}{$\mathrm{N}$} & No 3 & No 1 & No 2 & \\
\hline & N1 2 & N1 6 & N13 & \\
\hline & N2 1 & $\mathrm{~N} 23$ & $\mathrm{~N} 2$ & \\
\hline Total & 12 & 22 & 8 & \\
\hline
\end{tabular}

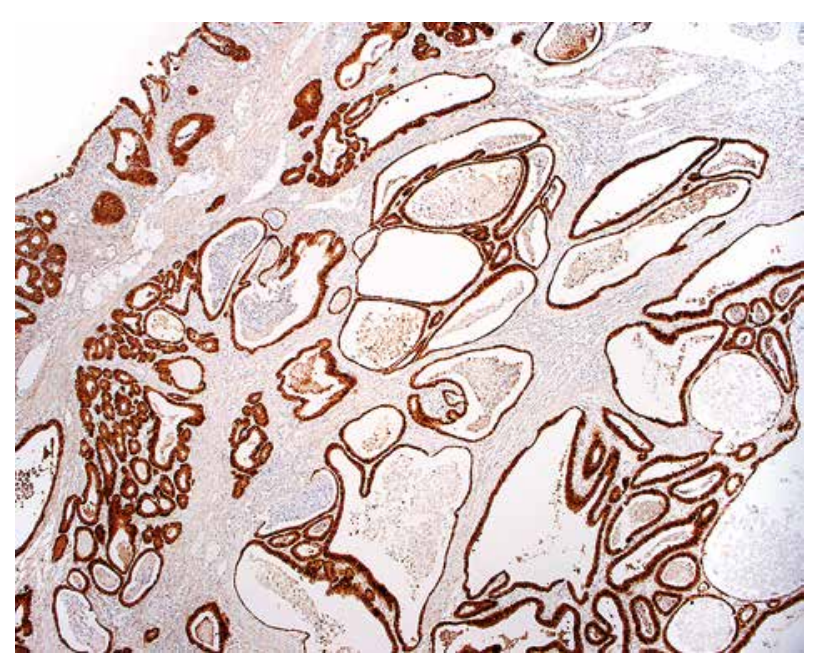

Fig. 1. Immuohistochemistry in the surgical specimen reduction of $\beta$-catenin in cell membrane staining $-\mathrm{M}(+)$ $\mathrm{N}(-)$. Objective magnification $20 \times$

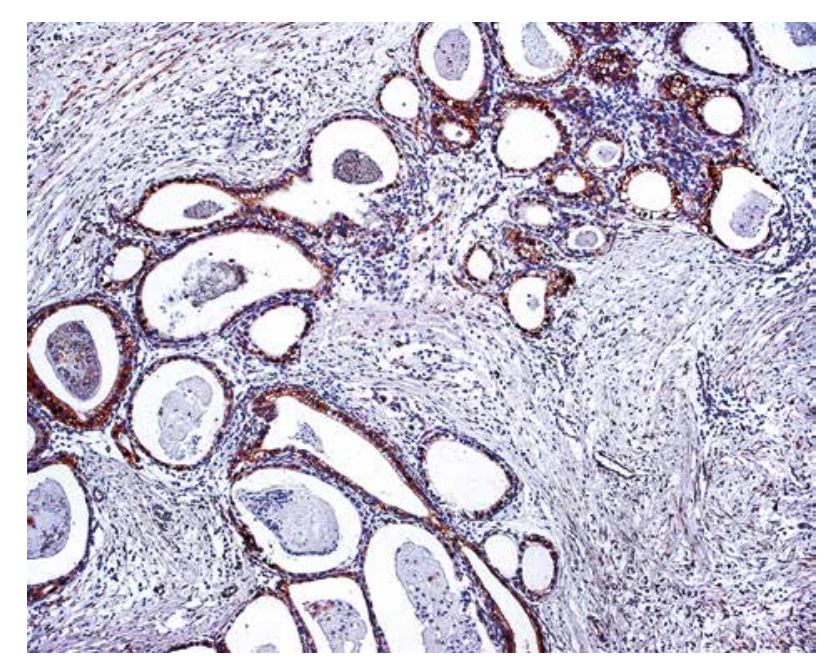

Fig. 2. Immuohistochemistry in the surgical specimen staining of cell's nucleus $\mathrm{M}(-) \mathrm{N}(+)$. Objective magnification $20 \times$ 
the depth of infiltration, but did not find any connection with tumor differentiation or lymph node metastases, whereas the authors observed a significant correlation with longer survival [11]. In our opinion the decisive factor for survival was the $\mathrm{T}$ stage. The role of catenin remains unclear. Its location and accumulation in the cell are connected with Wnt-pathway activation (coded group of family genes). The Wht gene family influences transmission of many signals in physiological processes such as cell differentiation, migration and transcription, but also its role in pathology is suggested, particularly in the process of carcinogenesis. The signals transmitted through Wnt are submitted by $\beta$-catenin and its action is regulated by the adenomatous polyposis coli APC/ GSK-3B complex. So stabilized catenin, controlled by phosphorylation process GSK-3B remains in the cytosol, whereas in the case of stimulation, it is transported into the cell nucleus in the form of T-cell factor complex causing cyclin D1, c-Myc, PPAR-sigma, and MMP 7 stimulation. Myc causes the induction of telomerase transcription, affecting an unidentified factor releasing p27 and blocking the cyclin sdk2. It is considered that catenin degradation may prevent APC and e-adherin mutations. Wnt and catenin activation may be connected to the process of oncogenesis and malignancy progression as well $[4,15]$. In this study, $\beta$-catenin staining distribution in esophageal adenocarcinoma (on the ground of Barrett's) type 1 and subcardial stomach carcinoma type 3 , depending on severity, differentiation, and Lauren's classification, was compared. Reduction of staining intensity was observed in the membranous part, while normal staining was observed in the cell nucleus. In this study a statistically significant difference in staining reduction, metastatic potential, and differentiation degree dependent on T stage was found. Gunther et al. found that nuclear expression of $\beta$-catenin may have a different effect on the course of rectal and colon carcinomas [16]. Our studies confirmed incorrect staining of $\beta$-catenin in 39 (61) patients diagnosed with adenocarcinoma of the esophagus type 1 and type 3 . The difference in staining for the individual types was not statistically significant. No statistically significant relation of staining reduction to patient survival or Lauren's classification was observed. Czyzewska et al. found a statistically significant dependence of $\gamma$-catenin staining, Lauren's classification intestinal type and degree of stomach cancer differentiation but did not find a correlation with survival. They found a strong correlation between stage of stomach cancer and metastatic potential [17]. Analyzing nuclear staining in tumor type 1 (AEG 1) and type 3 (AEG 3) and referring them to Lauren's classification, they found them in 13 (28\%) patients in Lauren's type 1
(7 in AEG 1) and 6 in AEG 3. Lee et al., analyzing patients with early stage stomach cancer, found that relocation, that is an increased level of $\beta$-catenin in the cytoplasm and cell nucleus, among patients with intestinal mucin phenotype in comparison with gastric mucin phenotype in stomach cancer, concerned 30\% of patients. At the same time they found a lack of association between loss of APC heterozygosity and relocation, while attributing the role of hypermethylation in the process of $\beta$-catenin relocation [18]. Woo et al. reported that staining of the nucleus and relocation took place in diffuse type stomach cancer in $27 \%$ of patients. The above is not confirmed by Ogasawa et al. They reported that staining of the cell nucleus occurred more often in intestinal type stomach cancer than in diffuse type $[19,20]$. It seems that $\mathrm{B}$-catenin relocation into the cell nucleus is possible due to c-Myc and cyclin D1 activation [21]. Bondi et al., analyzing colon cancer, did not find a correlation between $\beta$-catenin relocation and c-Myc or cyclin $\mathrm{D} 1$ activation. The authors noted that $\beta$-catenin relocation constituted metastatic potential while not noting this correlation in relation to c-Myc, cyclin D1 and $\gamma$-catenin. They assumed that the reason for that is metalloprotease, which is a target gene for the $\beta$-catenin/TCF pathway in colon cancer and can be activated independently from c-Myc and cyclin D1. Overexpression of MMP-7 is found in $80 \%$ of colon cancer cases and is an important factor in invasion and metastases [22]. The role of $\beta$-catenin relocation into the cell nucleus is emphasized by other authors, who prove its influence on malignant transformation in colon and pancreatic carcinomas [23, 24]. Incorrect $\beta$-catenin staining is observed in other organs such as liver, lungs, pancreas, and colon, although the mechanism of its activation can vary $[25,26,27,28]$. Xianhua et al., analyzing the survival in 262 patients diagnosed with non-small cell lung cancer observed incorrect $\beta$-catenin staining in $189(76 \%)$ patients, in correlation with Wnt 1 , overexpression c-Myc, cyclin $\mathrm{D} 1$, and $\mathrm{p} 53$. In the analyzed group, patients in whom positive staining was found had significantly shorter survival, but in multifactorial analysis Wnt 1 expression constituted an independent prognostic factor of survival $[25,29]$.

In conclusion, we observed a correlation of $\beta$-catenin reduction with $\mathrm{T}$ and $\mathrm{N}$ stage, without an influence on survival. Its relocation into the cell nucleus concerned 20 patients. However, the role of $\beta$-catenin in relation to progression of malignancy remains unclear. The biological effect of staining reduction provides for an increased metastatic potential.

The authors declare no conflict of interest. 


\section{References}

1. Altorki NK, Olveria S, Schrump DS. Epidemyology and molecular biology of Barrett's adenocarcinoma. Semin Surg Oncol 1997; 13: 270-280.

2. Sehdev A, Catencci DV. Gastroesophagalcancer: focus on epidemiology, classification, and staging. Discov Med 2013; 16: 103-111.

3. Van Aken E, De Wever O, Correia da Rocha AS, Mareel M. Dfective E-cadherin/catenin complexes in human cancer. Virchows Arch 2001; 439: 725-751.

4. Morin PJ, Sparks AB, Korinek V, et al. Activation of beta-catenin Tcf signaling in colon cancer by mutatios in beta-catenin or APC. Science 1997; 275: 1787-1790.

5. Siewert RJ, Stein HJ. Classification of carcinoma of the esophagogastric junction. Br J Surg 1998; 85: 1457-1459.

6. UICC-International Union Against Cancer. TNM classification of malignant tumours $7^{\text {th }}$ ed. John Wiley and Sons, New York 2010.

7. Lauren P. The two histological main types of gastric carcinoma: diffuse and so-caled intestinal-type carcinoma. An attempt at a histo-clinical calssification. Acta Pathol Microbiol Scand 1965; 64: 31-49.

8. Bailey T, Biddlestone L, Shepherd N, et al. Altered cadherin and catenincomplexes in the Barrett's esophagus-dysplasia-adenocarcinoma sequence: corelation with disease progression and dedifferention. Am J Pathol 1998; 152: 135-144.

9. Krishdandath KK, Tilnus HW, van Blankenstein M, et al. Reduced expression of the cadherin-catenin complex in oesphageal adenocarcinoma correlates with poor prognosis. J Pathol 1997; 182: 331-338.

10. Washington K, Chiappori A, Hamilton K, et al. Expression of beta-catenin, alpha-catenin, and E-cadherin in Barrett's esophagusand esophageal adenocarcinomas. Mod Pathol 1998; 11: 805-813.

11. Bian YS, Osterheld MC, Bosman FT, et al. Nuclear accumulation of beta-catenin is a common and early event during neoplastic progression of Barret oesophagus. Am J Clin Patho 2000; 114: 583-590.

12. Wijnhoven BP, Pignatelli M, Dinjens WN, Tilanus HW. Reduced p120ctn expression correlates with poor survival in patients with adenocarcinoma of the gastroesophgeal junction. J Surg Oncol 2005; 92: 116-123.

13. Wijnhoven BPL, Tucker ET, Dinjens WNM, et al. Biochemical analysisi and ubcellular distribution of E-cadherin-catenin in adenocarcinoma of the gastro-oesophageal junction. Anticancer Res 2004; 24: 1369-1376.

14. Jawhari AU, Noda M, Pignatelli M, Farthing M. Up-regulated cytoplasmic expression, with membranous distribution, of the substrat p120 (ctn) in gastric carcinoma. J Pathol 1999; 189: $180-185$.

15. Korinek V, Barker N, Morin PJ, et al. Constitutive transcriptional activation by beta-catenin Tcf complex in APC-/- colon carcinoma. Scince 1997; 275: 1784-1787.

16. Gunther K, Brabletz T, Kraus C, et al. Predictive value of nuclear beta-catenin expression for the occurence of distant metastases in rectal cancer. Dis Colon Rectum 1998; 41: 12561261.

17. Czyżewska J, Guzińska-Ustymowicz K, Ustymowicz M, et al. The expression of E-cadherin-catenin complex in patients with advanced gastric cancer: role in formation of metastasis. Folia Histochem Cytobiol 2010; 48: 37-45.

18. Lee SH, Kang HJ, Shin DH, et al. Expression of beta-catenin and its mechanism of delocalization in inteestinal-type early gastric cancer based on mucin expression. Histol Histopathol 2009; 24: 831-838.

19. Woo DK, Kim HS, Kang YH, et al. Altered expression and mutation of beta-cateningene in gastric carcinomas and cell lines. Int J Cancer 2001; 95: 108-113.
20. Ogasawara N, Tsukamoto T, Mizoshita T, et al. Mutation and nuclear accumulation of beta-catenin correlate with intestinal phenotypic expression in human gastric cancer. Histopathology 2006; 49: 612-621.

21. Utsunomiya T, Doki Y, Takemoto H, et al. Correlation of beta-catenin and cyclin D1 expression in colon cancers. Oncology 2001; 61: 226-233

22. Bondi J, Bukholm G, Nessland JM, Bukholm IRK. Expression of non-membranous B-catenin, c-Myc and cyclin D1 in relation to patient outcome in human colon adenocarcinomas APMIS 2004; 112: 49-56.

23. Herencia C, Martínez-Moreno JM, Herrera C, et al. Nuclear translocation of b-catenin during mesynchymal stem cells differentiation into hepatocytes is associated with a tumoral phenotype PLoS One 2012; 7 : e34656.

24. Cho IR, Koh SS, Min HJ, et al. Pancreatic adenocarcinoma up-regulated factor (PAUF) enhances the expression of -catenin, leading to a rapid proliferation of pancreatic cell. Exp Mol Med 2011; 43: 82-90.

25. Xu X, Sun PL, Li JZ, et al. Aberrant Wnt1/B-catenin expression is an independent poor prognostic marker of non-small cell lung cancer after sugery. J Thorac Oncol 2011; 6: 716724.

26. Heiser PW, Cano DA, Landsman L, et al. Stabilization of beta-catenin induces pancreas tumor formation. Gastroenterology 2008; 135: 1288-1300.

27. Seike M, Kondo T, Mori Y, et al. Proteomic analysis of intestinal epithelial cells expressing stabilized beta-catenin. Cancer Res 2003; 63: 4641-4647.

28. Fang QX, Lu LZ, Zhao ZS, et al. L1, $\beta$-catenin, and E-cadherin expression in patients with colorectal cancer: correlation with clinicopathologic features and its prognostic significance. J Surg Oncol 2010; 102: 433-442.

29. Włodarczyk J, Mueller J, Włodarczyk J. Lymph node micrometastasis adenocarcinoma located in the gastro-esophageal junction. Pol J Pathol 2013; 64: 170-174.

\section{Address for correspondence}

\section{Janusz Włodarczyk}

Department of Thoracic Surgery

Jagiellonian University Collegium Medicum

Krakow, Poland

e-mail: jr.wlodarczyk@gmail.com 